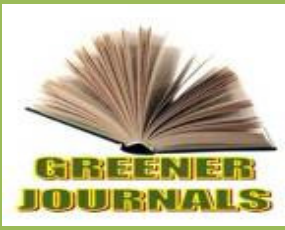

\title{
High Molecular Weight Glutenin Subunit Variation among Indian Wheat Varieties
}

\section{Bakshi Suman* and Bhagwat SG}

Nuclear Agriculture and Biotechnology Division, Bhabha Atomic Research Centre, Trombay, Mumbai-400085, India.

\section{ARTICLE INFO}

Article No.: 120816211

DOI: 10.15580/GJAS.2016.11.120816211

Submitted: 08/12/2016

Accepted: 19/12/2016

Published: 27/12/2016

${ }^{*}$ Corresponding Author

Bakshi Suman

E-mail: sumansud@barc.gov.in

Keywords:

Bread wheat, SDS-PAGE, quality score and chapatti
Improving wheat for end use quality is an important goal for wheat breeders. The composition of high molecular weight glutenin subunits (HMW-GS) contributes to a great extent in determining wheat quality for processing. The HMW-GS are known to be encoded by six genes located at the Glu-1 loci on the long arms of chromosomes 1A, 1B and 1D. The endosperm storage proteins of 62 Indian bread wheat cultivars were fractionated by sodium dodecyl sulphate polyacrylamide gel electrophoresis (SDS-PAGE) to determine their high molecular weight (HMW) glutenin subunit composition. In total, three alleles (Ax2*, $A \times 1$ or $A x$ null) at Glu$A 1$, seven allele/allelic pairs (Bx7, Bx7+By8, Bx7+By9, Bx20, Bx13+By16, $B x 13+B y 19$ and $B x 17+B y 18)$ at Glu-B1 and two allelic pairs (Dx2+Dy12 and Dx5+Dy10) at Glu-D1 were identified in the analysed varieties. Allele or allelic pair Ax2* (59.7\%) at Glu-A1, Bx17+By18 (27.4\%) at Glu-B1 and Dx2+Dy12 (69.4\%) at Glu-D1 were present most frequently in wheat varieties taken for study.

Quality score of varieties were ranged from 4 to 10 , with an average of 7.55 indicating vast genetic diversity among the varieties. The presence of subunits combinations in different varieties with low, medium and high gluten strength indicated that breeding wheat for bread, chapatti and biscuits is possible as per end use requirement. 


\section{INTRODUCTION}

High molecular weight glutenin subunit composition of a genotype heavily determines the end use quality of wheat. These high molecular weight glutenin subunits are encoded by genes at the Glu-A1, Glu-B1 and Glu-D1 loci on the long arm of homoeologuous chromosomes 1A, 1B and 1D, respectively (Payne and Lawrence, 1983). These loci encode an x-type subunit of higher molecular weight and a y-type subunit of lower molecular weight (Harberd et al., 1986). Most of the bread wheat cultivars possess from three to five active high molecular weight glutenin subunits due to silencing of some of these genes. The HMW-GS composition of a genotype is one of most important genetic factor for determining processing quality of wheat. There are differences in quality effects of glutenins coded by same locus. The alleles $A \times 1$ and $A \times 2^{*}$ of Glu-A1 have been found to have a better effect on bread-making quality compared to $A x$ null allele (Gupta et al., 1994; He et al., 2005). The High Molecular Weight subunits Dx5+ Dx10 of the Glu-D1 are correlated with higher dough strength, whereas the Dx2+ Dx12 alleles are correlated with poor bread-making quality (Branlard and Dardevet, 1985; Glanibelli et al., 2001).
Deletions at different HMW-GS loci on A,B or D genomes have shown to produce processed products with varied quality scores (Jondiko et al., 2012; Mondal et al., 2008; Uthayakumaran et al., 2003) and specialty breads with improved quality (Zhang et al., 2014). Rheological studies on deletions of different high molecular glutenin subunits loci at one genome and keeping intact HMW loci at other genome helps to investigate the role of each of these subunits on dough functionality (Jondiko et al., 2012; Mondal et al., 2008). Quality scores were assigned to individual high molecular weight glutenin subunits based on sodium dodecyl sulfate (SDS) sedimentation volume and alveographic parameter W (Payne et al., 1987; Pogna et al., 1992). Characterization of wheat genotypes for high molecular weight glutenin subunits is useful for breeders in choosing parental lines and selecting progenies with superior gluten quality.

In this study, the electrophoretic patterns of HMW glutenin subunits were analysed from 62 spring wheat cultivars released between 1965 and 2001. These cultivars were developed for five wheat agroclimatic zones of India, viz, North Western Plains Zone (NWPZ), Northern Hills Zone (NHZ), North Eastern Plains Zone (NEPZ), Central Zone (CZ) and Peninsular Zone (PZ) (Table1).

Table 1. HMW glutenin subunit at Glu1 loci, year of release and zone of cultivation of Indian wheat cultivars

\begin{tabular}{|c|c|c|c|c|c|c|c|c|}
\hline S.No. & variety & $\begin{array}{l}\text { Year of } \\
\text { release }\end{array}$ & $\begin{array}{l}\text { Zone } \\
\text { cultivation }\end{array}$ & of & Sowing conditions & GluA1 & GluB1 & GluD1 \\
\hline 1 & PBW175 & 1989 & NWPZ & & TS,RF & $2^{*}$ & $7+8$ & $2+12$ \\
\hline 2 & HD1949 & 1971 & Western UP & & TS,IR & $2^{*}$ & $7+8$ & $2+12$ \\
\hline 3 & HD2281 & 1983 & NWPZ & & TS,IR & $2^{*}$ & $7+8$ & $2+12$ \\
\hline 4 & HD1982 & 1974 & NEPZ & & LS/TS & $2^{*}$ & $7+8$ & $2+12$ \\
\hline 5 & HD2285 & 1983 & NWPZ & & LS/VLS,IR & $2^{*}$ & $7+8$ & $2+12$ \\
\hline 6 & PBW226 & 1989 & NWPZ & & LS,IR & $2^{*}$ & $7+8$ & $2+12$ \\
\hline 7 & HD2009 & 1975 & NWPZ & & TS,IR & $2^{*}$ & $7+8$ & $2+12$ \\
\hline 8 & HD2270 & 1984 & NWPZ & & LS,IR & $2^{*}$ & $7+8$ & $2+12$ \\
\hline 9 & HD2327 & 1982 & $C Z$ & & LS,IR & $2^{*}$ & $7+8$ & $2+12$ \\
\hline 10 & HD2380 & 1989 & NHZIPZ & & TS/LS,IR/RF & $2^{*}$ & $7+8$ & $2+12$ \\
\hline 11 & HD2501 & 1990 & $\mathrm{PZ}$ & & TS,IR & $2^{*}$ & $7+8$ & $2+12$ \\
\hline 12 & HDR77 & 1990 & NEPZ & & LS,RF & $2^{*}$ & $7+8$ & $2+12$ \\
\hline 13 & HUW234 & 1985 & NEPZ & & LS,IR & $2^{*}$ & $7+8$ & $2+12$ \\
\hline 14 & NW1014 & 1997 & NEPZ & & TS,IR & $2^{*}$ & $7+8$ & $2+12$ \\
\hline 15 & NP846 & 1965 & $\mathrm{NHZ}$ & & TS,RF/LIR & $2^{*}$ & $7+8$ & $2+12$ \\
\hline 16 & UP2338 & 1990 & $\mathrm{NHZ}$ & & TS,IR & $2^{*}$ & $17+18$ & $2+12$ \\
\hline 17 & HD2189 & 1979 & $\mathrm{PZ}$ & & TS,IR & $2^{*}$ & $17+18$ & $2+12$ \\
\hline 18 & Kalyansona & 1967 & NWPZ & & TS,IR & $2^{*}$ & $17+18$ & $2+12$ \\
\hline 19 & HD2329 & 1982 & NWPZ & & TS,IR & $2^{*}$ & $17+18$ & $2+12$ \\
\hline 20 & HD2385 & 1987 & FEZ & & LS/IR & $2^{*}$ & $17+18$ & $2+12$ \\
\hline 21 & WL711 & 1977 & NWPZ & & $\mathrm{TS} / \mathrm{IR}$ & $2^{*}$ & $17+18$ & $2+12$ \\
\hline 22 & Hindi62 & 1935 & NEPZ & & $\mathrm{TS} / \mathrm{IR}$ & $2^{*}$ & $17+18$ & $2+12$ \\
\hline 23 & Sonalika & 1965 & NW/NEPZ & & LS/IR & $2^{*}$ & $7+9$ & $2+12$ \\
\hline 24 & Kanchan & 1994 & $\mathrm{CZ}$ & & TS,IR & $2 *$ & $7+9$ & $2+12$ \\
\hline 25 & HD2687 & 1999 & NWPZ & & TS/IR & $2^{*}$ & $7+9$ & $2+12$ \\
\hline 26 & NP852 & 1965 & NEPZ & & TS/LS,IR & $2^{*}$ & $7+9$ & $2+12$ \\
\hline 27 & Lermarojo & 1965 & $C Z$ & & TS,IR & $2^{*}$ & $13+16$ & $2+12$ \\
\hline 28 & NW 1012 & 1997 & NEPZ & & TS,IR & $2^{*}$ & $13+16$ & $2+12$ \\
\hline 29 & Kundan & 1981 & NWPZ & & TS,IR & $2^{*}$ & $17+18$ & $5+10$ \\
\hline 30 & HI385 & 1975 & $C Z$ & & TS,RF & $2^{*}$ & $17+18$ & $5+10$ \\
\hline 31 & LOK1 & 1981 & $C Z$ & & TS/LS,IR & $2^{*}$ & $17+18$ & $5+10$ \\
\hline
\end{tabular}


Bakshi and Bhagwat / Greener Journal of Agricultural Sciences

\begin{tabular}{|c|c|c|c|c|c|c|c|}
\hline 32 & WH542 & 1992 & NWPZ & TS,IR & $2^{*}$ & $7+9$ & $5+10$ \\
\hline 33 & PBW299 & 1993 & NWPZ & TS,RF & $2^{*}$ & $7+9$ & $5+10$ \\
\hline 34 & HD2733 & 2001 & NEPZ & TS,IR & $2^{*}$ & $7+9$ & $5+10$ \\
\hline 35 & PBW435 & 2004 & NWPZ & LS, IR & $2^{*}$ & $7+9$ & $5+10$ \\
\hline 36 & NP824 & 1960 & & & $2^{*}$ & $7+9$ & $5+10$ \\
\hline 37 & Vidisha & 1996 & CZ & LS,IR & 1 & $17+18$ & $2+12$ \\
\hline 38 & Raj3077 & 1989 & NWPZ & TS/LS,IR & 1 & $17+18$ & $2+12$ \\
\hline 39 & GW190 & 1994 & $\mathrm{CZ}$ & TS,IR & 1 & $7+9$ & $5+10$ \\
\hline 40 & HS240 & 1989 & $\mathrm{NHZ}$ & TS,RF/LIR & 1 & $7+9$ & $5+10$ \\
\hline 41 & HUW206 & 1983 & NEPZ & TS,IR & 1 & $7+9$ & $5+10$ \\
\hline 42 & MACS2496 & 1991 & PZ & TS,IR & 1 & $7+9$ & $5+10$ \\
\hline 43 & NIAW34 & 1995 & PZ & LS/VLS,IR & 1 & $7+9$ & $5+10$ \\
\hline 44 & PBW373 & 1993 & NWPZ & TS,IR & 1 & 7 & $5+10$ \\
\hline 45 & PBW343 & 1996 & NWPZ & LS,IR & 1 & 7 & $5+10$ \\
\hline 46 & RAJ3765 & 1995 & NW/NEPZ & LS/VLS,IR & 1 & 7 & $5+10$ \\
\hline 47 & NI5439 & 1973 & PZ & TS,IR/RF & $\mathrm{N}$ & $17+18$ & $2+12$ \\
\hline 48 & NI5643 & 1978 & PZ & TS,IR & $\mathrm{N}$ & $17+18$ & $2+12$ \\
\hline 49 & NI747-19 & 1973 & $P Z$ & TS,RF/LIR & $\mathrm{N}$ & $17+18$ & $2+12$ \\
\hline 50 & C306 & 1965 & NWPZ/NEPZ & TS/RF & $\mathrm{N}$ & 20 & $2+12$ \\
\hline 51 & HW2004 & 1995 & $\mathrm{CZ}$ & TS,RF & $\mathrm{N}$ & 20 & $2+12$ \\
\hline 52 & $\mathrm{~N}-8223$ & 1991 & PZ & TS,RF & $\mathrm{N}$ & 20 & $2+12$ \\
\hline 53 & C-518 & - & - & - & $\mathrm{N}$ & 20 & $2+12$ \\
\hline 54 & C-591 & - & - & - & $\mathrm{N}$ & 20 & $2+12$ \\
\hline 55 & WG357 & 1973 & NWPZ & TS,IR & 1 & 20 & $2+12$ \\
\hline 56 & C273 & - & - & - & 1 & 20 & $5+10$ \\
\hline 57 & PBW 138 & 1987 & NWPZ & TS,IR & $\mathrm{N}$ & $13+19$ & $2+12$ \\
\hline 58 & NIAW301 & 2001 & PZ & TS,IR & $\mathrm{N}$ & $7+9$ & $2+12$ \\
\hline 59 & Sonora-64 & 1965 & NPZ/CZ & LS/LS,IR & 1 & $17+18$ & $5+10$ \\
\hline 60 & MP3054 & - & - & - & 1 & $17+18$ & $5+10$ \\
\hline 61 & Kharachia-65 & 1970 & All zones & TS,IR & $2^{*}$ & 20 & $2+12$ \\
\hline 62 & Chinese Spring & & & & $\mathrm{N}$ & $7+8$ & $2+12$ \\
\hline
\end{tabular}

\section{MATERIALS and METHODS}

Plant material: Seeds of 62 bread wheat varieties (Table 1) collected from different research and development institutions in India and maintained at Gamma field, Bhabha Atomic Research Center, Mumbai were used for this study. The grains were ground to fine powder and $10 \mathrm{mg}$ was weighted in $1.5 \mathrm{~mL}$ micro tube. $250 \mu \mathrm{l}$ of protein extraction buffer (Tris- $\mathrm{Hcl} 0.05 \mathrm{M}, \mathrm{pH} .8$, $0.02 \%$ SDS, 30.3\% urea, $1 \%$ 2-mercaptoetnanol) was added to each micro tube, boiled on flame for 10 minutes, and then after cooling centrifuged at 13000rpm for $10 \mathrm{~min}$. The high molecular weight glutenin subunit profile of wheat varieties was resolved by sodium dodecyl sulfate polyacrylimide gel electrophoresis (SDSPAGE) procedure according to Laemmlii (1970) and latter modified by Bhagwat and Bhatia (1993). The high molecular weight glutenin subunit variation was identified using the numbering system of Payne and Lawrence (1983). The quality scores was assigned to each HMWGS of a subunit pair using scoring described by Payne et al. (1987) and Pogna and Mellini (1986).

\section{RESULTS}

Amongst the 62 varieties analysed for high molecular weight glutenin subunits, three alleles and their corresponding subunits Glu-A1a (1), Glu-B1b (2*) and Glu-A1C (Null) with 16.1, 24.2 and $59.7 \%$ frequency were observed. Allelic variation at Glu-B1 locus showed seven alleles which included Glu-B1a (7), Glu-B1b (7+8), Glu-B1c (7+9), Glu-B1e (20), Glu-B1f $(13+16)$, Glu-B1g (13+19) and Glu-B1i (17+18) 4.8, 25.8, 24.2, $12.9,3.2,1.6$ and $27.4 \%$, respectively. The Glu-D1 locus showed two alleles with their subunits included Glu-D1a $(2+12)$ and Glu-B1d $(5+10)$ with frequency of 69.4 and $30.6 \%$. A total of 12 different alleles were identified on all three Glu1 loci (Table 2).

The maximum frequency of subunit $2^{*}$ and 1 at Glu-A1 locus indicated that varieties were improved for higher gluten strength compared to null allele in lowest frequency. The GluA1c (null) allele was found to exist only in combination with Glu-D1a $(2+12)$ in analysed varieties.

The coexistence of Glu-1Ac allele in combination with Glu-D1a allele was also observed earlier in Indian wheat genotypes Ram S. (2003). Glu-B1 locus showed higher frequency of three alleles Glu-B1b $(7+8)$, Glu-B1C (7+9) and Glu-B1i $(17+18)$ and contribute better gluten strength. The subunit 20 at Glu-B1 locus was found in eight of analysed varieties (Table 3 ).

The high molecular weight glutenin subunit combinations (allele at Glu-A1, Glu-B1 and Glu-D1) and their frequencies in 62 cultivars are given in table 3 . Among the 62 wheat varieties analysed, 19 different patterns were observed based on high molecular weight glutenin subunit combination at all three Glu-1 loci. The most frequent patterns were $2^{*}, 7+8,2+12$ (15 varieties), $2^{*}, 17+18,2+12$ (7 varieties) and $1,7+9,5+10$ and $2^{*}$, 
$7+9,5+10$ and $\mathrm{N}, 20,2+12$ (5 varieties each). Three of the analysed varieties namely Kundan, HI385 and LOK1 carried strong subunits at all loci $2^{*}$ at Glu-A1, 17+18 at Glu-B1 and 5+10 at Glu-D1. The major requirement for Indian wheat is for chapatti making and subunit 20 has great role to play for contributing medium gluten strength needed for dough for chapattis. Subunit 20 at Glu-B1 is present in combination with strong Subunit ' 1 ' at Glu-A1 and weak subunit $2+12$ at Glu-D1 locus in the cultivar Kharchia65. In five varieties C-306, HW2004, C-518, C591 and N8223, the subunit ' 20 ' is present with subunit 'Null' at Glu-A1 and 2+12 at Glu-D1 contributing weak gluten strength. The gel showing the allelic variation and HMW-GS patterns is presented in figure $1 \mathrm{a}$ and $1 \mathrm{~b}$.

The high molecular weight quality score calculated by adding individual score assigned to each subunit or subunit pair by Payne and Lawrence (1983) and Pogna et al., (1989). The most of varieties ( 90\%) analysed has higher gluten strength with Glu-1 score ranging from $8-10$ and only $10 \%$ of varieties has Glu-1 score of 5-7 (Table 3). This indicated that the wheat varieties bred in most zones are suitable for bread rather than chapattis and there is need to breed for varieties with medium Glu-1 score suitable for chapatti making quality.

Table 2. Allele frequencies of HMW Glutenin subunits at Glu-1 loci in $\mathbf{6 2}$ varieties of bread wheat

\begin{tabular}{|c|c|c|c|}
\hline Locus & Allele & $\begin{array}{l}\text { No. of varieties } \\
\text { carrying }\end{array}$ & Frequency \\
\hline \multirow[t]{3}{*}{ Glu-A1 } & $\mathrm{N}$ & 11 & 17.7 \\
\hline & 1 & 14 & 22.6 \\
\hline & $2^{*}$ & 37 & 59.7 \\
\hline \multirow[t]{7}{*}{ Glu-B1 } & 7 & 3 & 4.8 \\
\hline & $7+8$ & 16 & 25.8 \\
\hline & $7+9$ & 15 & 24.2 \\
\hline & 20 & 8 & 12.9 \\
\hline & $13+16$ & 2 & 3.2 \\
\hline & $13+19$ & 1 & 1.6 \\
\hline & $17+18$ & 17 & 27.4 \\
\hline \multirow[t]{2}{*}{ Glu-D1 } & $5+10$ & 19 & 30.6 \\
\hline & $2+12$ & 43 & 69.4 \\
\hline
\end{tabular}


Table 3. Combinations of HMW-GS alleles (Glu-A1, GluB1 and GluD1) and their frequencies in 62 bread wheat varieties from India

\begin{tabular}{|c|c|c|c|c|c|c|}
\hline Glu-A1 & Glu-D1 & Glu-B1 & Genotype & Frequency & $\begin{array}{l}\text { Glu1 } \\
\text { score }\end{array}$ & $\begin{array}{l}\text { Alveograph' } \\
W^{\prime}\end{array}$ \\
\hline \multirow[t]{7}{*}{$2^{*}$} & $2+12$ & $7+8$ & $\begin{array}{l}\text { PBW175,HD1949,HD2281,HD1982,HD2285,P } \\
\text { BW226,HD2009,HD2270,HD2327,HD2380,HD } \\
\text { 2501,HDR77,HUW234,NW1014,NP846 }\end{array}$ & 15 & 8 & 8 \\
\hline & & $17+18$ & $\begin{array}{l}\text { UP2338, HD2189, Kalyansona, HD2329, } \\
\text { HD2385,WL711, Hindi62 }\end{array}$ & 7 & 8 & 13 \\
\hline & & $7+9$ & Sonalika, Kanchan,HD2687,NP852 & 4 & 7 & 12 \\
\hline & & 20 & Kharachia-65 & 1 & 6 & 8 \\
\hline & & $13+16$ & Lermarojo,NW1012 & 2 & 8 & 12 \\
\hline & $5+10$ & $17+18$ & Kundan, HI385, LOK1 & 3 & 10 & 17 \\
\hline & & $7+9$ & $\begin{array}{l}\text { WH542,PBW299,HD2733,PBW435, NP824 } \\
\end{array}$ & 5 & 9 & 16 \\
\hline \multirow[t]{7}{*}{1} & $2+12$ & $7+8$ & HD2428 & 1 & 8 & 6 \\
\hline & & $17+18$ & Vidisha, Raj3077 & 2 & 8 & 11 \\
\hline & & 20 & WG357 & 1 & 6 & 6 \\
\hline & $5+10$ & $17+18$ & Sonora-64, MP3054 & 2 & 10 & 15 \\
\hline & & $7+9$ & $\begin{array}{llll}\text { GW190, HS240, } & \text { HUW206, } & \text { MACS2496, } \\
\text { NIAW34 } & & \\
\end{array}$ & 5 & 9 & 14 \\
\hline & & 7 & PBW343, PBW373, Raj3765 & 3 & 8 & 11 \\
\hline & & 20 & C273 & 1 & 8 & 10 \\
\hline \multirow[t]{5}{*}{$\mathrm{N}$} & $2+12$ & $17+18$ & NI5439, NI5643, NI747-19 & 3 & 6 & 10 \\
\hline & & $7+9$ & NIAW301 & 1 & 5 & 9 \\
\hline & & 20 & C-306,N8223, HW2004,C-518,C-591 & 5 & 4 & 5 \\
\hline & & $13+19$ & PBW138 & 1 & - & 4 \\
\hline & & & & & 7.45 & 10.45 \\
\hline
\end{tabular}

$\begin{array}{llllllllllllllllllllllllllll}1 & 2 & 3 & 4 & 5 & 6 & 7 & 8 & 9 & 10 & 11 & 12 & 13 & 14 & 1 & 2 & 3 & 4 & 5 & 6 & 7 & 8 & 9 & 10 & 11 & 12 & 13 & 14\end{array}$
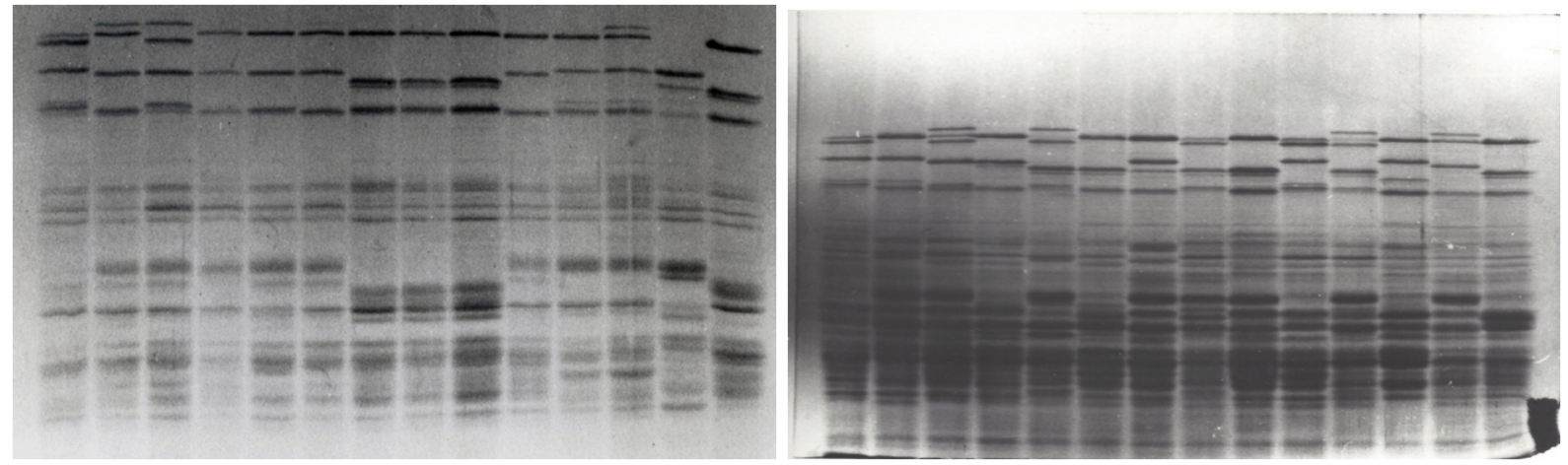

Figure1a:HMW-GS profile of varieties:1-NP824 $\left(2^{*}, 7+9,5+10\right), 2-\mathrm{WG} 357$ (1, 20, 2+12), 3-C273 $(1,20,5+10), 4-C 306(\mathrm{~N}, 20,2+12), 5-\mathrm{C} 518$ (N, 20, 2+12), 6-C591(N, 20, 2+12), 7-NI5439 (N, 17+18, 2+12), 8-NI5643 (N,17+18, 2+12), 9-NI747-19 (N, $17+18,2+12), 10-\mathrm{N} 8223(\mathrm{~N}, 20,2+12), 11-\mathrm{NIAW} 30$ $1(\mathrm{~N}, 7+9,2+12), 12-\mathrm{NIAW} 34(1,7+9,5+10), 13-$ NI5749 $(\mathrm{N}, \quad 13+16, \quad 2+12), \quad$ 14-HD2329 $(2 *, 17+18,2+12)$
Figure1b:HMW-GS profile of varieties1-WH42(2*, $7+9,5+10), 2-$ Sonalika $(2 *, 7+9,2+12), 3-$ C273 (1, 20, 5+10), 4-Kharchia-65 $(2 *, 20,2+12)$, 5-Sonora $64(1,17+18,5+10), 6-N P 846(2 *, 17+18,2+12), 7-$ Lermarojo $64 \quad(2 *, 13+16,5+10), \quad 8-\mathrm{HI}-385$ $\left(2^{*}, 17+18,5+10\right)$, 9- Hindi62 ( $\left.2^{*}, 17+18,2+12\right)$, 10-PBW435 (2*, 7+9, 5+10), 11-MP3054 $(1,17+18,5+10), 12-C h i n e s e$ spring $(\mathrm{N}, 7+8,5+10)$, 13-WG357 (1, 20, 2+12), 14-Kalyansona (N, 


\section{DISCUSSION}

The analysis of glutenin subunits has proved useful for diversity studies and to optimize the variation in wheat germplasm for quality improvement of new wheat selections. The results of present study revealed a broad range of variation for allelic variants at Glu-1 loci and combination of these alleles at three loci led to 19 different high molecular weight glutenin subunits patterns. Since the plant material for study was varieties released for different cultivation zones, however, there was no association of presence of varieties with specific subunit or subunit combination in the zones of cultivation.

Each zone has varieties differing for gluten strength based on HMW-GS constitution at all three Glu loci. It has been established in number of studies that glutenin protein of wheat grain plays an important role in processing quality of wheat particularly for bread and pastas (Branlard and Dardevet, 1985; Ng and Bushuk, 1988). Wheat varieties originated in East Asia countries possess predominantly allele Glu-D1a coding for subunits $2+12$ (Fang et al., 2009; Liu et al., 2007) and contribute weak gluten strength. The results of present study also confirm the same and Glu-D1a coded subunit $2+12$ is present in $69 \%$ of varieties compared to Glu$D 1 d$, which is in $30 \%$ of varieties. This correspond that the HMW-GS compositions of wheat varieties originated in different countries of the world reveal the purpose for which they were commonly used. It has been observed in studies that alleles known for superior bread-making quality of hexaploid wheat are found in considerably lower frequency in countries such as China or Japan ( $\mathrm{Li}$ et al., 2009;Tanaka et al., 2003). The presence of subunits $1 / 2^{*}$ at Glu-A1, 7+8, $17+18$ at Glu-B1 and $5+10$ at Glu-D1 resulted in better rheological properties for bread making. Whereas for chapatti making qualities which is indigenous requirement of India and other Asian countries require medium gluten strength and can be achieved by addition of subunit 20 with strong subunit at other Glu loci. Sreeramulu et al., (2004) mentioned the importance glutenin subunits for chapatti making quality. The subunit 20 was more prevalent in old varieties, which are no more in cultivation. However, there is need to bring subunit 20 in combination with other subunits at Glu-A1 and Glu-D1 locus in breeding lines for selection of varieties with medium gluten strength for chapatti making quality.

\section{REFERENCES}

Bhagwat SG and Bhatia CR (1993). Selection for quality in early generation based on the HMW subunits of glutenin in bread wheat. Indian J. Genet. 53: 208214.

Branlard G and Dardevet M (1985). Diversity of grain protein and bread wheat quality. II. Correlation between high molecular subunits of glutenin and flour quality characteristics. J. Cereal Sci. 3: 345354.

Fang J, Liu Y, Luo J, Wang Y, Shewry PR and He G (2009). Allelic variation and genetic diversity of high molecular weight glutenin subunit in Chinese endemic wheats (Triticum aestivum L.). Euphytica 166:177-182.

Gianibelli M, Gupta RB, Lafiandra D, Margiotta B and MacRitchie F (2001). Polymorphism of high $\mathrm{Mr}$ glutenin subunits in Triticum tauschii: characterization by chromatography and electrophoretic methods. J. Cereal Sci. 33:39-52.

Gupta RB, Paul JG, Cornish GB, Palmer GA, Bekes F and Rathjen AJ (1994). Allelic variation at glutenin subunit and gliadin loci, Glu-1, Glu-3 and Gli-1 of common wheats. I. Its additive and interaction effects on dough properties. J. Cereal Sci. 19: 9-17.

Harberd NP, Bartels D and Thompson RD (1986). DNA restriction fragment variation in the gene family encoding high molecular weight (HMW) glutenin subunits of wheat. Biochem.Genet. 24: 579-596.

He ZH, Liu L, Xia XC, Liu JJ and Pena RJ (2005). Composition of HMW and LMW glutenin subunits and their effects on dough properties, pan bread, and noodle quality of Chinese bread wheats. Cereal Chem. 82: 345-350

Jondiko TO, Alviola NJ, Hays DB, Ibrahim A, Tilley M and Awika, JM (2012). Effect of high-molecularweight glutenin subunit allelic composition on wheat flour tortilla quality. Cereal Chem. 89:155-161.

Laemmli UK (1970). Cleavage of structural proteins during assembly of the head of bacteriophage T4. Nature 227: 680-685.

Li Y, Huang Ch, Sui X, Fan Q, Li G and Chu X (2009). Genetic variation of wheat glutenin subunits between landraces and varieties and their contributions to wheat quality improvement in China. Euphytica 169: 159-168.

Liu Y, Xiong ZY, He YG, Shewry PR and He GY (2007). Genetic diversity of HMW glutenin subunit in Chinese common wheat (Triticum aestivum L.) landraces from Hubei province. Genet. Resour. Crop Evol.54: 865-874.

Mondal S, Tilley M, Alviola JN, Waniska RD, Bean SR, Glover KD and Hays DB (2008). Use of nearisogenic wheat lines to determine the glutenin composition and functionality requirements for flour tortillas. J. Agric. Food Chem.56:179-184.

$\mathrm{Ng}$ PKW and Bushuk W (1988). Statistical relationship between high molecular weight subunits of glutenin and bread making quality of Canadian grown wheats. Cereal Chem.65: 408-413.

Payne PI, Nightingale MA, Krattiger AF and Holt LM (1987). The relationship between HMW glutenin subunit composition and the bread-making quality of British-grown wheat varieties. J. Sci. Food Agric. 40: 51-65. 
Payne PI (1987). Genetics of wheat storage proteins and the effect of allelic variation on bread making quality. Ann. Rev. Plant Physiol. 8: 141-153.

Payne PI and Lawrence GJ (1983). Catalogue of alleles for complex gene loci, Glu-A1, Glu-B1 and Glu-D1 which code for high molecular weight subunits of glutenin in hexaploid wheat. Cereal Res. Commun. 11: $29-35$.

Pogna NE and Mellini F (1986). Alla ricerca delle basi biochemiche e genetiche della qualita del glutine.L'Inform Agr 42: 65-66.

Pogna NE, Mellini F, Beretta A and Deruffo A (1989). The high-molecular-weight glutenin subunits of common wheat cultivars grown in Italy. J. Genet. Breed. 43: 17-24.

Pogna NE, Radaelli R, Dackevitch T, Curioni A, Dal Belin Perufo A (1992). Benefits from genetics and molecular biology to improve the end use properties of cereals. In: Feillet P (ed) Cereal chemistry and technology: a long past and a bright future, Montpellier, France, INRA, 83-93.
Ram S (2003). High Molecular Weight Glutenin Subunit Composition of Indian Wheats and their Relationships with Dough Strength. J. Plant Biochem. Biot.12:151-155.

Sreeramulu G, Banerjee R, Bharadwaj A and Vaishnav PP (2004). Understanding the functionality of Wheat High Molecular Weight Glutenin Subunits (HMWGS) in Chapati Making Quality. In: The Gluten Proteins; The Royal Society of Chemistry, 162-165.

Tanaka H, Tomita M, Tsujimoto H, YasumuroY (2003). Limited but specific variations of seed storage proteins in Japanese common wheat (Triticum aestivum L.). Euphytica 132:167-174.

Uthayakumaran S, Lukow OM, Jordan MC and Cloutier $S$ (2003). Development of genetically modified wheat to assess its dough functional properties. Mol. Breed. 11:249-258.

Zhang P, Jondiko TO, Tilley M and Awika JM (2014). Effect of high molecular weight glutenin subunit composition in common wheat on dough properties and steamed bread quality. J. Sci. Food Agr. 94: 2801-2806. 